\title{
A Lie Is a Lie: The Ethics of Lying in Business Negotiations
}

\author{
Charles N. C. Sherwood \\ London School of Economics and Political Science
}

\begin{abstract}
I argue that lying in business negotiations is pro tanto wrong and no less wrong than lying in other contexts. First, I assert that lying in general is pro tanto wrong. Then, I examine and refute five arguments to the effect that lying in a business context is less wrong than lying in other contexts. The common thought behind these arguments-based on consent, self-defence, the "greater good," fiduciary duty, and practicality-is that the particular circumstances which are characteristic of business negotiations are such that the wrongness of lying is either mitigated or eliminated completely. I argue that all these "special exemption" arguments fail. I conclude that, in the absence of a credible argument to the contrary, the same moral constraints must apply to lying in business negotiations as apply to lying in other contexts. Furthermore, I show that for the negotiator, there are real practical benefits from not lying.
\end{abstract}

Key Words: business ethics, negotiation, lying, consent, self-defence, fiduciary duty

B usiness ethics has become an essential component of any business school curriculum or similar management training. While this is generally to be welcomed, it carries with it a risk: that we take its very subject title-business ethics - to imply that there is a distinct set of moral rules that apply only to business and that are significantly different from those moral rules that apply in society more generally. The suggestion is that there is some kind of exemption whereby normal ethical standards need not be so strictly adhered to in a business context. I believe this suggestion should be firmly resisted.

Perhaps the most notable case of this has been the half-century-long debate, ignited by Albert Carr (1968), on the permissibility of lying in business negotiations. This is the subject of what follows. My central claim is that lying in business negotiations is pro tanto wrong and no less wrong than lying in other social contexts. I argue, furthermore, that such lying is both unnecessary and, in most cases, ultimately to the disadvantage of the negotiator.

In section 1, I assert that lying in general is pro tanto wrong, that is, morally impermissible, unless there are exceptional countervailing moral factors that carry even greater weight. My insistence on the consistent application of this normative principle is the foundation of the argument that follows.

Section 2 lays out what I call the special exemption thesis: variously the explicit claim or implicit assumption that lying in business negotiations is not wrong, or at least not as wrong as lying in other contexts, that is, that business negotiations are in 
some way "exempt" from the moral rules that govern lying in general. The empirical evidence suggests that this view is widely held. But those who defend this view must explain what special circumstances justify this exemption. Where is the moral disanalogy that makes permissible in this "special" instance what is elsewhere impermissible?

In section 3, I examine the five main arguments used by apologists to defend the special exemption thesis: the argument from consent, the argument from selfdefence, the argument from the "greater good," the argument from fiduciary duty, and the argument from practicality. The common thought behind these arguments is that the particular circumstances which are characteristic of business negotiations are such that the wrongness of lying is either mitigated or eliminated completely. I seek to demonstrate that each of these arguments is seriously flawed.

Finally, in section 4, I reiterate that the burden of proof rests with the apologist. The apologist must show that there is a disanalogy, a moral difference, between lying in business negotiations and lying in ordinary social interaction. Because the apologist has failed to do this, consistency requires that the two be treated alike. I conclude that it is time for business practitioners 1) to acknowledge that lying in negotiations is pro tanto wrong and no less wrong than lying in other contexts and 2) to recognise that such lying is both unnecessary and, in most cases, ultimately to their own disadvantage.

Let us consider the following scenario:

Zach was at a conference in Philadelphia to promote his firm's latest pharmaceutical packaging machine. As he left the conference hall, he was approached by a regular customer, Abe: "Zach, that's an impressive machine you've developed. We could be a buyer. But we would be looking for a discount. Only fair to tell you." Zach was fully prepared to offer a sizeable discount. His firm had received no customer enquiries at all to date, and his boss had made her feelings very clear: they must place one of these prototype machines quickly to test it in action and, if that meant all but giving the thing away, then so be it. But Zach also knew there would be huge plaudits for him personally if he could keep that discount to an absolute minimum. "Abe, you know I can't do that. This is the most advanced machine of its generation. There is considerable interest from other customers; and my boss will not permit discounting. Absolutely not. I'm sorry." Abe looked somewhat deflated, but the two of them stepped into a nearby bar and continued the negotiation over a beer. When they parted an hour later, they had agreed the deal. The discount was 20 per cent.

In the preceding account, Zach lies to Abe. He asserts things he knows to be untrue with the intent to deceive and thus disadvantage Abe. There has been no evidence of interest from other customers, and Zach's boss is not absolutely set against a discount - indeed, quite the reverse - as Zach knows. To assert the opposite is to lie. Yet, many see this kind of "bluffing" as just normal, acceptable negotiating tactics and therefore morally permissible. And even those who consider it morally reprehensible seem, in the main, to find it less so than outright lies told in other contexts (for a review of the empirical evidence, see section 2). Is this view valid?

An obvious starting point would be to ask whether such lying is legal. And yet the position is not entirely clear. As Richard Shell (1991, 93-94) points out, under US 
law at least, there is no duty of "good faith," that is, no general obligation to consider anything other than one's own advantage. Zach's claim that there is interest from other customers could be considered a fraudulent misrepresentation, but the instances of courts finding fictitious claims of outside interest to be fraudulent are very few (96-97). As for Zach's lie concerning the availability of a discount, there is a specific exemption in rule 4.1.a of the American Model Rules of Professional Conduct for "estimates of price or value placed on the subject of a transaction and a party's intentions as to an acceptable settlement" (Gorlin 1990, 372). In other words, in this area, even the lawyers are legally allowed to lie (Shell 1991, 96; Dees and Cramton 1991, 140; Applbaum 1999, 105-6; Burr 2001, 11-12; Peppet 2002, 92). So, although there are "many gray areas" (Shell 2018, 218), Zach probably remains, for practical purposes anyway, on the right side of the law. But is his behaviour acceptable? Is it morally permissible? I shall argue that it is not.

\section{DEFINITION AND MORALITY OF LYING}

There is an extensive literature covering the definition of lying (for reviews, see MacIntyre 1994; Saul 2012; Mahon 2015). Much of it, though, is devoted to explaining distinctions-some of them very fine ones-that we draw between lies and a careless indifference to the truth ("bullshit") (Frankfurt 2005, 33-34, 54-55), between deceptive and so-called non-deceptive lies ("bald-faced lies") (Chisholm and Feehan 1977, 159; Carson 2006, 289-90; Sorensen 2007, 259-63), between lying to others and lying to oneself (self-deception, connivance) (Barnes 1994, 87-102), between adversarial lies and benevolent lies ("white lies," jests, prosocial lies) (Erat and Gneezy 2012, 724; Harris 2013, 12-21; Levine and Schweitzer 2015, 89), between intentional lies and "false" use of language (linguistic error/malapropism, metaphor, hyperbole, irony) (Saul 2012, 15-19), and between intentional statements of untruth and unintentional statements of truth (Fallis 2009, 38-39).

However, these distinctions have only a limited bearing on most business negotiations, at least as far as concerns material lies. More often than not, the latter involve lies of a narrow variety: ones that are targeted at others rather than oneself; that are serious and adversarial rather than light-hearted or benevolent; that are literal rather than literary; and that are intentional statements of known untruth. I therefore intend to employ a rather simplified definition: you lie if, and only if, you assert something you believe to be false with the intent to deceive and disadvantage another. In doing so, I take what I consider to be the common-sense position that light-hearted hyperbole or other language that is clearly not intended to deceive-statements offered with a smile, such as "you scared me to death" or "my children will not eat tonight unless you agree this deal"- do not constitute lies. They are not intended to be believed, nor are they intended to disadvantage another. This also eliminates from my definition so-called prosocial lies that, while being misleading, are intended to benefit the counterparty (Levine and Schweitzer 2015, 89; Gaspar, Levine, and Schweitzer 2015, 307). My focus, then, is on what Sanjiv Erat and Uri Gneezy $(2012,724)$ identify in their taxonomy of lies as "selfish black lies." 
Significantly, my preceding definition is limited to active lying, that is, lies of commission. Such lies are of course part of a broader category of deception that includes paltering (use of a factually truthful statement to create a false impression) and passive deception (misleading through omission). I accept that such paltering (Rogers et al. 2017, 461, 465-71) and misleading omissions (Schweitzer and Croson 1999, 243-44) are ubiquitous and can, in some instances at least, be as damaging as outright lies. But I am anxious here to maintain a focus on a specific and clearly identifiable form of behaviour: active lying. By contrast, deception covers a huge range of behaviours - to quote the title of one recent article, it comes in "Fifty Shades" of grey (Gaspar, Methasani, and Schweitzer 2019, 62)_-and as a result is somewhat amorphous. This of course limits the application of my findings, but it does at least establish a well-defined starting point from which other work can follow.

As a general matter, I assert that lying is wrong: it is morally impermissible. As Sissela Bok $(1999,30)$ puts it, "truthful statements are preferable to lies in the absence of special considerations"; that is, there is a moral "presumption against lying." But, as Bok implies, this presumption cannot be rigid. It must allow for "special considerations," exceptional circumstances when the wrong of lying is outweighed by other moral concerns. Contrary to the well-known views of Augustine ([395] 2016, 17), Wesley ([1785] 1831, 276-77), and Kant ([1797] 2016, 83-84), a categorical prohibition of lying is untenable. In Kant's classic test case of the murderer at the door seeking the fugitive within, almost all of us would feel that lying about the whereabouts of the potential victim was not only permissible but also obligatory, to avoid the greater wrong of murder (Strudler 2005, 463). But such exonerating circumstances are rare.

My opening claim, then, is that lying is pro tanto wrong, that is, morally impermissible, unless there are exceptional countervailing moral factors that carry even greater weight. I assert but do not seek to defend this position, other than to point out that it is a widely held view that seems to span many cultures. In an eight-country study of 1,583 students, Harry Triandis and colleagues $(2001,85)$ concluded that "in all cultures people feel bad when they lie, especially when they lie a lot ... suggesting that all [recognize] that lying is wrong." This appears to be close to "a moral universal" (also Williams 2002, 60; Tyler, Feldman, and Reichert 2006, 69; Gerlach, Teodorescu, and Hertwig 2019, 4; Abeler, Nosenzo, and Raymond 2019, 1116-17; Sunstein 2021, 26, 50).

I have no more to say on lying generally. Instead, in the argument that follows, I focus on the second, more contentious part of my claim, viz. that lying in business negotiations is no less wrong than lying in other contexts.

\section{THE SPECIAL EXEMPTION THESIS}

A number of authors have claimed that lying in business negotiations is acceptable, because different rules apply from those that prohibit lying in other contexts. One of the earliest of these, Carr (1968, 143-53), argued at a wider level that "business operates with a special code of ethics," its own "rules of the game, set by law," and 
that therefore management is morally bound only to obey the law. Others take a different view, accepting that there are moral obligations in business that extend beyond the law. But they seek to make a particular exception for lying in business negotiations - what I call the special exemption thesis.

Variants of this thesis are widely held. Fritz Allhof $(2003,283)$ argues that "bluffing in business is morally permissible," Alan Strudler $(1995,810)$ that "it is permissible to bluff ... by lying about my reservation price," Karl Aquino $(1998,197)$ that in a negotiation it is possible for a statement to be "untrue" and yet "ethically justified," and Thomas Carson $(1993,323)$ that "it is not expected that one will speak truthfully about one's negotiating position." Carson, Richard Wokutch, and Kent Murrmann $(1982,13)$ accept that "bluffing and other deceptive practices ... do constitute lying" but nonetheless consider them "typically morally permissible," while James Michelman $(1983,255)$ insists that "given the constraints of economic competition, one must negotiate by means of deception." All these statements would appear to imply that there is something special about the process of negotiation that places it beyond the normal moral constraints that attach to other social contexts. And this perspective can be detected, too, in the broader philosophical literature. For example, Bernard Williams (2002), who concludes that "living in the truth is just a better way" (263), insists that nonetheless "areas of commercial activity" may create "special circumstances," adding that "it is often said that no sensible person expects to hear the truth when buying a used car from a dealer" (109-10).

Empirical research suggests that this attitude extends beyond philosophers and business academics to the community at large. Using a combination of twenty-two in-depth interviews and 240 responses to questionnaires, Vincent-Wayne Mitchell and Joseph Chan (2002) created a "Consumer Ethics Index" (12) to compare UK consumer attitudes to different kinds of unethical behaviour. Of the fifty forms of behaviour compared (13-15), six involved lying and one of these lying in the context of a negotiation. This lie- "not telling the truth about your financial position when negotiating the price of a new automobile"-was rated morally less wrong than all but one of the other forms of lying. These others included such seemingly trivial things as "saying one group member lost his/her ticket for an event as an excuse for getting in front of the queue and getting in sooner" and "telling the waiter that the 'soup is too cold or it has a funny taste' when there is no problem." The only lie that was considered morally less wrong than the one related to negotiation was "lying about one's age to get a pint of beer." This might suggest that the average Western consumer has relatively few qualms about lying in a financial negotiation.

One must be wary of judging a population at large on such a small sample, but this picture is supported by several further studies among business school students, which reveal a similar preparedness to diverge from the truth in a negotiating setting. In one such study, Karl Aquino and Thomas Becker (2005, 666-70) simulated a negotiation between a large car and truck manufacturer ("General") and a potential supplier ("Midwest") concerning the price of a key component: an aluminium hood. Different scenarios were tested, but in all cases, the ninety-six MBA students representing General knew the hood would become obsolete in three years, making the contract significantly less attractive for the supplier. When asked directly by the 
Midwest representatives about the expected length of the contract, 2 per cent told the truth, 43 per cent concealed the truth, and 55 per cent lied. In another simulation, involving seventy-five graduate business students, Ann Tenbrunsel (1998, 332-34) found that a similar proportion, 55 per cent, lied about crucial information submitted to an arbitrator to achieve a negotiating advantage. And in a further simulation, involving a faulty computer hard drive and conducted among 148 students, Schweitzer and Croson $(1999,241)$ found that 39 per cent lied when asked a direct question and 25 per cent lied unprompted. Similar cases of dishonesty have been observed in many other studies (O'Connor and Carnevale 1997, 504; Murnighan et al. 1999, 332; Boles, Croson, and Murnighan 2000, 247; Brandts and Charness 2003, 125; Croson, Boles, and Murnighan 2003, 154; Volkema, Fleck, and Hofmeister-Toth 2004, 321, 332; Gneezy 2005, 387-88; Guidice, Alder, and Phelan 2009, 543).

All the studies cited here were focussed on Western capitalist democracies with typically individualist cultures, where priority is often given to personal rather than group interests. More recent research has examined whether similar attitudes to lying and other ethically ambiguous negotiating tactics extend to other cultures that may be more collectivist. The eight-country study by Triandis et al. $(2001,83)$ found that in a simulation where students were asked to declare the production capacity of their company's plant, regardless of the country or culture, at least 80 per cent factually lied, with participants from Asian countries being among those who exaggerated the most. Other such studies have also indicated that a preparedness to lie in business negotiations is prevalent across cultures and is by no means a uniquely Western characteristic (Rivers and Lytle 2007, 5-10; Banai et al. 2014, 681; Zhang, Liu, and Liu 2015, 137). Indeed, there is growing evidence that collectivist cultures, such as that of China, may disproportionately favour lying to business counterparts, because the latter are seen as part of an outgroup; that is, they are outside the relevant collective (Ma 2010, 132; Ma, Liang, and Chen 2013, 651; Rivers and Volkema 2013, 26).

These various studies are not straightforward to interpret, because the parameters differ and the sample sizes are in most cases small. The broad conclusion, though, seems clear: across cultures, 1) lying generally is seen as wrong, but 2) lying in a business negotiation is seen as acceptable to many. The latter is viewed as morally less problematic than lying in many other contexts.

So, what is the basis for this distinction? Where is the disanalogy, the moral difference, that allows the apologist to justify this special exemption, to make permissible in a business negotiation what is in other contexts impermissible? Apologists offer five main arguments for such a moral difference. I will evaluate, and seek to refute, each in turn.

\section{REFUTATION OF THE APOLOGIST ARGUMENTS FOR THE SPECIAL EXEMPTION}

\subsection{Argument from Consent}

\subsubsection{Tacit Consent}

The argument from consent is often framed as an analogy between business negotiations and a game. Carr and others cite poker, while Carson has a preference for the 
board game Risk. The implication is that a special set of rules apply, rules that do not prize honesty as it is prized elsewhere. Carr $(1968,143-53)$ argues that these special rules represent a "ritualized" convention according to which truth is not required, whereas Carson (1993, 322-23) suggests that in negotiations, "each party consents to renouncing the ordinary warranty of truth." Allhof $(2003,286-87)$ goes further, insisting that negotiation is a game and one where the moral permissibility of lying is grounded in a principle of mutual "endorsement" (also Lewicki 1983, 87; Beach 1985, 194; Holley 1998, 633). All these theses ultimately rest on the concept of tacit consent. Whether those involved have acknowledged a ritual, have agreed that statements are not warranted to be true, or have mutually endorsed falsity, the underlying premise is the same: that everyone in the negotiation-everyone "at the table" - has accepted that they may lie and be lied to.

I argue on two grounds that such universal consent does not exist. First, the argument from tacit consent faces a reductio ad absurdum; and second, it is simply inconsistent with the facts.

To take the first, suppose we grant, for the sake of argument, that there is universal tacit consent that lying is admissible. If so, then it cannot make a substantive difference if that tacit consent is made explicit. At least, if that were not the case, then the position would appear troubling: it would fail the test of publicity that has been thought morally imperative among philosophers from Immanuel Kant ([1795] 1917, 184-85) to John Rawls $(1971,133)$. Simply to give voice to what is already understood and accepted by all should not be problematic.

But, if the claimed tacit understanding is made explicit, then the dialogue of negotiation becomes all but emptied of meaningful content. Let us take, as an example, our opening scenario. Assuming that the supposed tacit consent is made explicit, the dialogue would read somewhat as follows:

AвE: Zach, we would be looking for a discount. Only fair to tell you.

ZACH: Abe, you know I can't do that. There is considerable interest from other customers, and my boss will not allow a discount. Absolutely not. I'm sorry. Although I must add that this may or may not be true.

Zach's reply is only one short step from the following:

ZACH: Abe, you know I can't do that, although perhaps I can. There is considerable interest from other customers, although this may not really be the case, and my boss will not allow a discount, but then perhaps she will. Absolutely not-well, maybe. I'm sorry. I must add that all this may or may not be true.

What Zach says here is not false. Indeed, in grammatical or logical terms, it is a tautology and therefore necessarily true. However, the dialogue has been emptied of meaning. It no longer fulfils the task of communication. It is neither truth nor lie. It draws close to Harry Frankfurt's (2005, 42-43) "bullshit" or "hot air": "it is mere vapor."

The apologist might object to the assumption in my argument that a tacit agreement of lying applies to everything. In reality, she might feel, it applies 
only to certain areas of negotiation. There is evidence, for example, that people are more willing to lie when the potential harm to their counterparty is trivial than when it is more serious (Gneezy 2005, 387-88). But the same result holds. Consider the case of a used car salesman and customer. The salesman might argue that, while he would never lie about the car's brakes, there is nonetheless a tacit understanding that he may lie about the air conditioning. Given that, it is of course possible for the two parties to have a meaningful conversation about the brakes. But, if both salesman and customer have really tacitly agreed that whatever words the salesman utters in relation to the air conditioning need not relate in any way to the truth, what possible purpose can a discussion of the air conditioning fulfil? It is meaningless.

My argument, however, remains open to a further objection. Strudler (1995), in particular, claims that deceptive statements can still fulfil a purpose as a signalling device, a "trial balloon" (817) indicating intensity of feeling. He suggests that they can "express one's commitment to a price range or to the idea that one has something quite valuable to offer" (816-17). But how effective can such verbal signalling be if there is a tacit agreement that everything said on the subject may be a lie? Any statement so qualified loses much, if not all, its force. I would suggest that there are other, more effective ways of communicating value than signalling with lies, such as describing the unique features and efficacy of the product or service on offer. But I will return to Strudler's argument when I examine the consequentialist case for lying in section 3.3.

The point here is that communications during a negotiation are only effective if there is some presumption of truth. And they can only serve their purpose to the extent that they are believed to be true, or at least likely to be true. If statements are genuinely "unwarranted"- - either true or false with unspecified probability—and are understood as such, then rational negotiators will ignore them. And, actually, this is what often happens in practice. To return again to our scenario, if Abe believes absolutely nothing Zach says, he is as likely to reply as follows:

AвE: Zach, let's cut the bullshit. What's your best price? Just give me a number.

There is an illuminating parallel here with the world of corporate social responsibility (CSR). David Hess and Thomas Dunfee $(2007,19)$ have noted that the lack of assurance (regulation or standardised requirements) around corporate statements on CSR has rendered them "cheap talk," which increasingly cynical stakeholders learn to heavily discount or even ignore. They call this a "babbling equilibrium": meaningful communication has ceased. In the environmental arena, this kind of unsupported, distrusted, and largely empty communication even has its own name: greenwash.

In short, meaningful communication and exchange require some degree of trust. In contrast - and to borrow from Ivan Preston's (1994, 201) study of the advertising market - "when we act with utter distrust we stop acting; we paralyze ourselves. We can no longer participate in the marketplace." It seems unlikely that negotiators have really chosen that option, that is, to set aside all trust-tacitly or otherwise. 
This reductio ad absurdum leaves us with two possible explanations of Zach's lying. The first is that Zach really believes there is a tacit agreement that he may lie and intends his lie to be understood as empty of meaning, innocent "babbling," "mere vapor," in which case, we might ask why he bothers. The second is that Zach knows there is no such tacit agreement and hopes to be believed, at least to some degree. His lie has purpose. He seeks to influence Abe. I believe the latter explanation is more credible.

Importantly, I do not argue that empty conversation is morally impermissible. Instead, my point is that the liar does not intend his communication to be understood as empty; he aims to be believed, at least partially. This undermines the argument from consent. After all, a genuine tacit agreement that he may lie would defeat the very purpose of him lying.

\subsubsection{Universal Consent and the "Closed Circle"}

My second argument against the case for consent is rather more straightforward: such consent is not consistent with the facts. The apologist argument is that, while we each have a right not to be harmed by others' lies, each of us has consented to give up that right in the context of a negotiation. But, because a right can only be surrendered by the holder of that right ( $I$, for example, cannot give up your rights), this implies universal consent among those involved in negotiations. And yet it is empirically false that all business negotiators have accepted that they may be lied to in this way.

The act of participation in an adversary game, even when the "rules" are known to everyone, does not itself signal consent, because, as Bok $(1999,83)$ says, "there may be no way for [you] to 'leave the game,'" or at least, the costs of doing so may be very high. In a similar vein, expectation is not the same thing as consent: that you know you may be lied to does not mean that you agree to being lied to (Applbaum 1999, 4, 116). As Gil Hersch $(2020,213)$ argues, just because your daily commute requires you to live in a high-crime neighbourhood does not mean that you consent to being mugged.

In his reply to Allhof, Carson $(2005,401)$ makes this same point: "It is simply false that all participants in business negotiations endorse the practice of misstating one's reservation price." He goes on to cite the example of a naive adolescent buying a used car and insists that he, Carson, like that naive adolescent, does not consent to being lied to (also Sullivan 1984, 9; Koehn 1997, 1449; Provis 2000b, 8; Piker 2002, 339).

Behind this lies an important fact of human nature: most of us are very trusting (Sunstein 2021, 73-76). As Roderick Kramer (2009) succinctly puts it, "to trust is human" (70). Kramer believes that this "presumptive trust" (71) derives from our evolutionary history, where it increased the survival chances of vulnerable infants. Whether that is the case or not, he is surely right that, for many of us at least, "trust is our default position" (71). And, for many of us, that trust is not set aside simply because we have entered into a business negotiation. The many financial scandals associated with the breach of that trust - for example, the fraudulent sale of payment protection insurance in the United Kingdom and the Madoff Ponzi scheme in the United States - are clear evidence of how trusting many of us are. 
My claim, though, that there is no universal consent is open to challenge by reference to an extreme environment like the tourist bazaar. Here it can be argued that the expectation of being lied to is so marked and so universal that anyone who chooses to bargain there must surely consent to being lied to. Their very act of voluntary participation signals their consent. I accept that there is some substance to this objection. But my acceptance is qualified in two respects. First, for many people, this is a grudging consent: their consent is, as it were, forced from them as a condition of their participation. It is a case of "consent or go without." Second, and perhaps more importantly, the clearly inessential nature of the purchases involved is vital to the claim of voluntariness. Such deemed consent cannot be extended to truly essential purchases, such as the provision of shelter, clothing, food, or basic transportation for one's family. Nor can it be applied to a broad array of typical business dealings, where business managers, by the nature of their roles, are required from time to time to participate in negotiation. Given the obligatory nature of this requirement, their mere participation cannot be assumed to imply their consent to being lied to.

The apologist argument from consent faces a further challenge. Most theories of consent require that such consent (tacit or explicit) be sought and received from all those affected-all those who could potentially be harmed. The apologist makes an implicit assumption that, as in a game of poker or Risk, all those affected are seated "at the table": that they form what is sometimes called a "closed circle." Only thus can the apologist claim the required level of consent. This assumption is generally fair in poker. Most of the time, it is true that only those around the table are materially affected by the outcome of the game. But, while this may be largely true in poker, it is almost uniformly not the case in business negotiations. Almost never do business negotiations affect only those at the negotiating table (Badaracco 1997, 19-20; Applbaum 1999, 116, 134). As Dees and Cramton (1991, 152) point out, "third parties, who had no choice, may be affected." They give the example of small communities impacted by labour negotiations with the community's major employer (also Bowie 1985, 288, 290; Koehn 1997, 1452). Equally, we may return again to our opening scenario, where Abe is buying a pharmaceutical packaging machine. If the machine costs more, so in all likelihood will the pharmaceuticals. Ultimately, this implies greater costs or less availability for customers, including public health systems, patients, and taxpayers. In addition, the outcome of Zach and Abe's negotiation will impact their various competitors. In business, there is no closed circle.

The argument from consent, then, not only faces a reductio ad absurdum. It is also inconsistent with the facts. Everybody "at the table" has not consented to being lied to, and many of those affected by the negotiation are not even seated "at the table" in the first place.

\subsection{Argument from Self-Defence}

Some have defended lying in business negotiations on the grounds of self-defence. For example, Dees and Cramton $(1991,148)$ condone a policy of "defensive dishonesty," whereas Strudler $(2005,462)$ claims that "certain deceptive acts that 
occur in negotiation are morally acceptable because of their defensive function" (also Tenbrunsel 1998, 331).

Carson has been a particularly strong advocate of this approach with his "principle of self-defence," or SD, as he abbreviates it. Carson's SD states, "It is permissible to lie or attempt to deceive others about one's negotiating position" provided that various necessary and jointly sufficient conditions are met. The real work is done by the first of these conditions, which is that "one's negotiating partner is doing the same and is likely to harm one thereby." Carson (2010a, 356-57) emphasises that it must be "clear that the other person is misstating his intentions." In the absence of such clarity, "the default position should be not to lie or deceive others" (Carson 2010b, 194-95).

This conditionality severely restricts the application of SD. This is because you can sometimes know with a high degree of certainty that your counterparty is lying; and you can at other times be harmed by your counterparty lying; but it is hard to see how both can be the case at one and the same time. After all, you cannot be harmed by deception when you are not deceived. You may be harmed, of course, by a lack of information, but a lack of information is not itself a lie. A lie requires a false statement, and if you do not believe that false statement, it seems unlikely that it can harm you. It follows that, when self-defence would be justified, it is not actually needed. Indeed, in the absence of any harm to be averted, your counter-lies cease to be self-defence and become mere retaliation. Thus the conditions required to justify SD produce a "nil set."

Carson anticipates this objection. In response, he argues that you can be harmed by deception even when you are not deceived - that is, that the set is not nilbecause even failed attempts at deception can cause one to "reveal one's own preferences" through "expressions of emotion" and "create uncertainty or fears that weaken one's resolve" (Carson 2010b, 197). Carson may be right. Perhaps there are emotional pressures that a liar can exert even when his lies are detected as such. For example, a bald-faced lie might demonstrate dominance and disrespect, placing the counterparty at a psychological disadvantage. But this feels like a marginal argument, and Carson admits as much in his concluding remark: "nonetheless, I concede that this objection supports the view that my SD principle seldom justifies lying or deception in negotiations" (2010b, 197; also 2010a, 358).

However, there is a rejoinder available to an advocate of SD. It is possible that you might know your counterparty is lying or will lie to you, without knowing for sure which statements of hers are lies. A clear case is when the counterparty makes two statements that are inconsistent: both cannot be true, but you may not know which is false. In theory at least, this is an instance when you can know the counterparty is lying and may be harmed by that lie. Again, though, this feels very much at the margin. After all, if you know for certain that your counterparty is lying regarding at least some of what she states, are you really likely (absent other supporting evidence) to attach great credence to anything she states, and sufficient credence to expose you to harm? It seems unlikely.

All the foregoing casts doubt on whether you can knowingly be harmed by a lie; but, even if you do know you are being harmed, it is far from obvious that lying in 
response would remove that harm. In the case of physical attack, most justifications of self-defence sanction actions that are designed to parry the attack, that is, to fend off the blows and prevent further blows. It is difficult to see how retaliatory lying would achieve anything equivalent.

The apologist could perhaps argue that retaliatory lying, though not removing the original harm, might nonetheless neutralise it in some way, through a balancing of the scales. In this vein, she might appeal to a legal distinction between justifiable conduct and excusable conduct. Joseph Heath (2018) characterises the latter as morally undesirable behaviour that has become habitual throughout a business domain and which all participants must emulate to remain competitive. Such behaviour is seen as excusable in that, although it is wrong, it is not considered blameworthy (523-26). The implication would be that, if everybody else is lying, then you cannot be blamed for lying yourself to "level up the playing field." But Heath sets two conditions for such unjustifiable yet excusable conduct. First, the cost of not behaving in this way-in this case, of not lying-must be "unreasonably high" (529). This is rarely the case with lying, as I seek to demonstrate in section 3.5. Second, the party must not condone the practice as a whole but instead must take "positive action" (529) to curtail it. This would certainly rule out pre-emptive lying. And, as Heath goes on to warn, under this " "everyone else is doing it' argument" (520), there is a real danger that "we had no choice, our competitors were doing it" can all too easily slip "between 'were doing it' and 'were going to do it,' 'were probably going to do it,' or 'might have done it", (526).

What is clear is that Carson's "principle of self-defence" at best justifies the apologist position in a very narrow group of cases. For example, it certainly could not justify Zach lying to Abe, as he does in our opening scenario. There is no evidence that Abe has lied first, or indeed ever lies, and therefore no case for selfdefence as described by Carson.

The self-defence argument might, though, be reframed by the apologist in the language of reciprocity: if your counterparty lies to you and thus fails to show you what Stephen Darwall $(1977,40)$ calls "moral recognition respect," surely you are then relieved of any obligation not to lie to her. But this line of argument sits most easily with acts that are supererogatory, where my uncalled-for gesture of help, kindness, or courtesy places you under an implicit obligation to reciprocate, and, to the contrary, where my failure or refusal to make such a gesture leaves you without any such obligation. It sits much less easily with circumstances involving harm. To take the extreme case, you would not typically view the obligation to refrain from murder as one imposed by the principle of reciprocity. If someone commits murder, you may have a right of self-defence, but not a right to reciprocate. In like fashion, the principle of reciprocity alone seems insufficient to justify inflicting harm through lying. Such a response would best be described not as reciprocation but rather as retaliation. Stripped of its defensive aspect, reciprocity of this kind becomes a case of "a wrong for a wrong," one harm justified by another - the morality of the gangland and the blood feud.

This concept of negative reciprocity is similar in some respects to a more permissive version of the argument from self-defence advocated by Dees and Cramton 
(1991, 144). They argue for a "notion of defensive fair-play," based on their "mutual trust principle." This formulation has gone through revision over time, and it remains unclear whether it should be seen first and foremost as a moral or a prudential maxim (Dees and Cramton 1995, 829-30). But it essentially states that the obligation to negotiate honestly is diminished, or indeed eliminated, when there is an absence of mutual trust between the parties. In effect, this inverts the burden of proof stipulated by Carson. To justify lying, you need no longer prove that your counterparty is lying. Instead, you need only satisfy yourself that you have no reason to trust that he is not lying.

While Carson's SD seems too restrictive, Dees and Cramton's mutual trust principle would appear too permissive. In many instances, it would seem to raise again Heath's concern and justify what Roy Sorensen $(2007,262)$ calls a "pre-emptive lie," with all the escalation effects that entails. It is, as the authors acknowledge, a principle suited to "a Hobbesian state of nature" and counter-intuitive to most of us (Dees and Cramton 1995, 828). Furthermore, it is vulnerable to extension ad absurdum. As Strudler (1995, 807-8) points out, "the Principle seems to allow one to do anything to one's opponent, no matter how horrible." If I am permitted to lie to you in the absence of positive evidence that you will not lie to me, then presumably the same principle must apply to other forms of pre-emptive injury, such as unprovoked physical assault. In other words, in the absence of evidence that you are not going to attack me, it would appear morally permissible for me to attack you. Such a pre-emptive right of injury, whether it be through physical assault or lying, is untenable.

Advocates of these self-defence arguments face, then, a two-horned dilemma. On one hand, if Zach is required to be nearly certain that he is being lied to by Abe (in line with Carson's SD), lying in self-defence is almost never justified, because Abe's claimed deception cannot harm Zach when Zach is not deceived; and anyway, it is unclear how a counter-lie renders the original lie harmless. On the other hand, to the extent that this requirement is weakened (in line with Dees and Cramton's mutual trust principle), then to that extent, Zach is permitted to lie pre-emptively, but also, by extension of the same principle, to commit all sorts of other unprovoked injuries-injuries that cannot possibly be justified. It appears that any apologist case based on self-defence is thus, at best, extremely limited.

It seems the apologist must still look elsewhere for a cogent defence of the special exemption. The foregoing debates rest on foundations that are essentially deontological in character. They assume implicitly that people have rights and, in particular, a right not to be lied to, but that this latter right can be waived through consent or forfeited if, by threatening others, you give them a right of self-defence. I will now turn to an apologist argument from a different ethical tradition, consequentialism, that is, an argument that appeals to the consequences of lying to assess its moral rightness or wrongness.

\subsection{Argument from the "Greater Good"}

Applbaum (1999, 6, 187-97), Jonathan Cohen (2002, 118), and Nathaniel Davis (2016, para. 2) all see the "greater good" argument lurking behind many of the 
special exemption claims of the "adversary professions"-in business as well as in law and government. Each cites Adam Smith ([1776] 2012) and his theorem of the invisible hand. They do not suggest that Smith himself advocated lying. But they do claim that behind many of the arguments marshalled in support of the permissibility of lying in negotiations, there rests an assumption that, through mechanisms similar to those Smith describes, society's greater interest is served-specifically, that the self-interested pursuit of individual gain, in an adversarial negotiation, generates a clearing price for the market and ensures an efficient allocation of resources to the benefit of society as a whole; and crucially that, should part of that amoral, selfinterested pursuit of individual gain involve the use of deceit, this is permissible as long as it is an essential element of the mechanism that serves that morally laudable objective, the greater good. Or such anyway is the apologist case. It is, for example, an argument that has been employed to defend "spoofing" (deceptive orders and order cancellations) in high-frequency trading (Cooper, Davis, and Van Vliet 2016, 3, 10-13). But, as Applbaum $(1999,180)$ warns, "the appeal to the good ends of adversary institutions in equilibrium is notoriously underdemonstrated." A closer analysis is needed. Let us break down the key claims into two components.

First, is business negotiation, in particular price negotiation, vital to the "greater good"? This is contestable, but I will concede to the apologist that, in many instances, the answer is yes - at least in a liberal, capitalist, market economy.

But the apologist must also prove a second contention: that lying is an essential element of that business negotiation. This contention is much more doubtful and, I argue, false. It is important to note that the question here is not about protecting the interests of individual protagonists (I address this in section 3.5); rather, it is about the successful maintenance of the system for the benefit of society as a whole. In this context, it is very hard to see how lying is beneficial, let alone essential. Seen from the perspective of society as a whole, negotiation is about communicating relative availability and need so that these can be better matched. Lies are false communications. They introduce an information asymmetry, where one party has more information than the other, that is, knows the truth while the other is deceived. To return to the example of spoofing, it has been argued that, because other traders are able to see only half the trade, they are left "misinformed about the real supply and demand for financial contracts" (Hersch 2020, 218). In economists' terms, such misinformation, or asymmetry of information, represents a market failure. An efficient market requires properly matched information (Applbaum 1999, 192; Heath 2014, 37), and lying undermines this. This would suggest that, although a suitable process of negotiation may be crucial to delivering the greater good, that process should not include lies.

This conclusion, however, faces a potential objection. While the consequentialist case for lying in negotiations remains largely implicit, one particularly strident apologist, Strudler (1995, 818), does make the case explicitly with his "mutual advantage view." Posing the question "Is deceit wrong?" he insists that "no plausible case [can] be made even for the prima facie wrongness of deception" (812). Strudler argues that, on the contrary, deception is "a mutually advantageous tool" (813) that creates "a safe device for indirect communication" (818). He bases this, as we saw 
earlier, on the role of lying as a form of signalling. In other words, Strudler believes that lying actually improves the flow of information and, presumably therefore, enhances market efficiency and the general welfare (816-17).

Dees and Cramton $(1995,824)$ have pointed out that there is one sense at least in which Strudler's argument is self-defeating. If the purpose of deception is really to improve information transparency and to enhance the knowledge of the counterparty, then it is not deception. And in practice, we do not treat it so. Sometimes a comment is so very obviously figurative, light-hearted, or clearly intended to mean something beyond its face value that it cannot be interpreted literally. It is not intended to deceive, nor to disadvantage, and, consistent with our opening definition, does not therefore constitute a lie. But this does not characterise most lying in negotiations, especially when such lying is between parties who do not know each other well or relates to matters other than reservation prices. Most "deceit" is just that: intended to deceive (even if it actually fails to do so). It does not aim to improve information transparency or market efficiency.

It is possible, though, to put a different interpretation on Strudler's mutual advantage view. One might accept that individual deception is self-interested and intended to deceive, while arguing that somehow these various deceptions interact with each other to create a mutually advantageous outcome. This would appear consistent with Strudler's $(1995,818)$ signalling thesis and with his unconventional claim that lying is the solution to the lack of trust between the parties, rather than its cause. But again, it is hard to see how Strudler's logic would apply beyond disclosure of the reservation price, and even then, it would seem to fly in the face of empirical evidence that supports the more conventional direction of causality, that is, that it is lying that creates distrust, not the other way around (Boles, Croson, and Murnighan 2000, 255; Tyler, Feldman, and Reichert 2006, 75; Schweitzer, Hershey, and Bradlow 2006, 15, 17; Gaspar and Schweitzer 2013, 168). Indeed, Raymond Friedman (1993), studying success and failure in labour negotiations, has concluded that "the one factor that is consistently most important is trust" (435) and that the crucial contributor to that trust during the bargaining process itself is "believing what the other side says" (451). It is by not lying, by instead developing a reputation for speaking honestly, by building confidence, that you earn the right to be believed, to have what you say taken at face value. It might seem naively simple, but the most effective communication is when someone who is trusted tells the truth.

The worst instances of the deceit that Strudler advocates can lead to a failure to transact at all. Strudler $(1995,816)$ describes a personal experience which seems to illustrate just this point. He recounts an incident in Madrid when a taxi driver "feigned shock" at the sight of Strudler's extensive luggage, declaring that there was simply too much to be accommodated in the car (a lie). Strudler took this at face value and chose to rent a car instead, leaving the taxi driver outraged that Strudler had not sought to negotiate further. Strudler seems to feel that this demonstrates the importance of correct signalling, but it appears an equally potent illustration of the adverse consequences of lying in a negotiation.

As Leslie John $(2016,117)$ warns, far from being an essential element of negotiation, "lying ... can be a real impediment to the creation of value in 
negotiation." There is a danger that, as in Strudler's case, false statements about the parties' bargaining positions lead to a breakdown in negotiations, where actually a mutually beneficial transaction is possible (Dees and Cramton 1995, 825; Rogers et al. 2017, 468-69). This is particularly the case with reservation prices. For example, let us suppose that Abe is actually prepared to pay 90 per cent of list price, while Zach and his boss, pushed to the limit, would accept as little as 75 per cent. This is clearly a transaction that ought to be easily achievable and in the interest of all. After all, there is an overlap in acceptable outcomes (i.e., a cooperative surplus) equivalent to 15 per cent of list price. But if Zach insists (falsely) that his boss will not countenance any discount and Abe (equally falsely) claims he can pay no more than 70 per cent of list price, and they believe each other's lies, then there is a danger that they will fail to reach agreement at all and walk away. A 15 per cent cooperative surplus has been transformed, through mutual lying, into an apparent 30 per cent gap, and a "deal that should happen" from a consequentialist perspective instead collapses.

Furthermore, there is a wider concern. As I have argued already, repeated lying undermines trust (Boles, Croson, and Murnighan 2000, 255; Tyler, Feldman, and Reichert 2006, 75; Schweitzer, Hershey, and Bradlow 2006, 15, 17; Gaspar and Schweitzer 2013, 168; Sunstein 2021, 27). This in turn threatens the cooperative efforts that underpin social life (Lewicki 1983, 74). For example, Dan Ariely (2009, 215) reports a conversation with an Iranian student at MIT who complained that the lack of a platform of trust in his country meant that no one would pay in advance or offer credit and all hiring had to be done within the family. Normal commercial relations were not possible.

As Asha Rao and Stuart Schmidt (1998, 669) argue, trust "limits transaction costs," because it encourages more informal exchange of information, without the need for exhaustive validation (also Arrow 1973, 314; Burr 2001, 14), and conversely, lying increases those costs and can even lead to a collapse in the means of exchange. George Akerlof (1970) vividly illustrates this latter point with his seminal analysis of "lemons" (overpriced, poor quality used cars) in the automotive industry. Because of a lack of honest information, customers are only prepared to pay the price consistent with the average quality of all cars available in the market. Sellers of highquality cars know their cars are worth more than this and therefore withdraw from the market. As a result, the average quality and consequent price of cars in the market declines, and more sellers withdraw. Before long, the only cars available for sale are the lemons, customer trust is undermined, and the market is threatened with collapse, thus highlighting "the major costs of dishonesty" (Akerlof 1970, 495; also Arrow 1973, 307-8). As Roger Sullivan (1984, 2) warns, this "leads to the destruction of the system of value traded for fair value on which business as an enterprise is based" (also Hare 1992, 11-12).

Communication and cooperation within a society rely on the presumption that most people are telling the truth most of the time. The survival of this presumption cannot be taken for granted. Empirical research reveals not only a tendency for lying to lead to more lying by the individual concerned (Barnes 1994, 44; Shell 2018, 177; Gaspar, Methasani, and Schweitzer 2019, 72); it also has an escalatory effect, where 
early use by one party encourages subsequent use by the other (Volkema, Fleck, and Hofmeister-Toth 2004, 333; Tyler, Feldman, and Reichert 2006, 75; Sobral and Islam 2013, 290-91; Olekalns, Kulik, and Chew 2014, 24). This "ethical fading," as it has been called, weakens those very bonds that hold societies together and permit communal life (Tenbrunsel and Messick 2004, 224; Rees, Tenbrunsel, and Bazerman 2019, 28). But this may still understate the importance of trust. After all, for most of us, it has more than just an instrumental value: "trust is a basic human aspiration" (Banai et al. 2014, 673), something that meets one of our fundamental needs as social beings. It has a status that borders on a good in its own right- "a social good to be protected just as much as the air we breathe or the water we drink" (Bok 1999, 26).

In short, the consequentialist case for negotiation is strong; but the consequentialist case for the permissibility of lying in negotiation is not. There is no necessary conflict between the search for truth and the search for agreement. Indeed, quite the reverse is true. And the costs of lying for society as a whole are considerable.

\subsection{Argument from Fiduciary Duty}

The fourth apologist argument is somewhat different in character, or at least in its target. It does not need to contest that lying in business negotiations is pro tanto wrong. Instead, it argues that whether it is pro tanto wrong or not is largely irrelevant in practice, because any pro tanto wrongness is consistently outweighed by another consideration: management's fiduciary obligation to its stakeholders. The argument runs that managers may be obliged to lie to optimise the outcome for the other stakeholders in the enterprise. This is their fiduciary duty, and it stands before any queasiness concerning falsehood.

There has of course been a long-standing debate as to which stakeholders are owed such an obligation. The traditional emphasis on owners is associated with Milton Friedman (1962, 1970), whereas others, led by R. Edward Freeman (1984), have advocated a more inclusive approach, extending to customers, suppliers, employees, and the community at large. A popular solution among practitioners has been to refer to a duty to protect and further the interests of the company, thus avoiding any specific or preferential allegiance, while retaining the notion of a fiduciary obligation to promote the greater interest of a wider constituency that still falls short of society as a whole.

This particular language is very much tied to that of business, but it has its parallels elsewhere. It is part of what the lawyer Charles Curtis $(1951,16)$ calls "the special moral code which governs a man who is acting for another." Applbaum has made a close study of the legal profession in this regard, examining the moral status of lawyers making statements in or out of court that they themselves believe to be false, based on an avowed obligation to promote the interests of their clients. This "argument of constituted description," as Applbaum $(1999,89)$ characterises it, claims that a lawyer fulfils different roles as a lawyer and as an individual. In the former role, he has a duty to his client which places him beyond many of the strictures of any broader moral code. As Curtis $(1951,9)$ puts it rather baldly and contentiously, "one of the functions of a lawyer is to lie for his client." 
A similar distinction is evident, too, in the British Civil Service. Sir Michael Quinlan (1993, 542), a past permanent secretary of the Ministry of Defence, describes the need occasionally to bow to ministerial wishes and defend "a square circle." He does not countenance direct lying but does believe that unelected officials, once they have argued the case in confidence with ministers, are duty bound to promote it in public, whatever their private reservations (Applbaum 1999, 61-74).

These different appeals to a fiduciary obligation - the business executive's based on a duty to protect his company's interest, the lawyer's based on a similar duty to protect that of her client, and the civil servant's based on the principle of democratic accountability - vary in degree, but they all point to a common distinction between principal and agent. The argument is conceptually similar in all three cases: in the event of conflict, the agent has a moral obligation - to protect and further the interests of the principal-that overrides other moral considerations. Accused of deceit or other wrongdoing, the agent may respond that they are merely fulfilling the duty to their principal that their role requires. If, in the case of a negotiation, protecting the interest of the principal entails lying or distortion, and that is the will of the principal, then such also is the obligation of the agent.

I believe this argument fails for four reasons. First, it is questionable whether lying really is in the interest-at least the long-term interest-of the principal. In the corporate context, we should ask whether it truly benefits the company to have its executives lie on its behalf. Most progressive companies put considerable store by their reputation for honest dealings, a reputation often promoted and defended at great expense. But I will leave this point aside for now and take it up again later, when I examine the argument from practicality in section 3.5.

Second, the weakness of the principal-agent argument comes into much clearer focus when we view the situation from the perspective of the victim, viz. the recipient of the lie. Through the actions of others and through no fault of their own, the victim's interests have been set back; the victim has been wronged. The agent and principal may seek to shuffle between them the responsibility for this wrong, but such shuffling does not make it go away. It does not negate the wrong. The moral impermissibility of the lie is not extinguished (Applbaum 1999, 11, 109).

Furthermore, the principal-agent argument can be extended ad absurdum, in much the same way as was the case with the permissive version of the self-defence argument. If the agent can justify lying in the interests of her principal, then why can she not similarly justify any manner of other wrongs, all the way from fraud to murder? This is no merely abstract concern. Many appalling crimes have been excused in just this manner. In particular, a common defence of war crimes has rested on a duty to carry out orders from higher authority - in other words, the duty of agents to fulfil the wishes of their principals. To take the very obvious example of the Nuremberg Trials, as the Holocaust Encyclopedia reminds us, "the defendants generally acknowledged that the crimes they were accused of occurred but denied that they were responsible, as they were following orders from a higher authority" (US Holocaust Memorial Museum 2021). I am not of course suggesting that lying 
can be equated with genocide, but the argument from fiduciary duty is essentially the same in both cases, revealing its structural weakness.

Finally, the fiduciary duty defence of lying fundamentally misinterprets the relationship between principal and agent. If the negotiator is, to employ Friedman's $(1970,211)$ language, "the agent of the individuals who own the corporation" or, for that matter, of the stakeholders more broadly, then it follows that the manager's obligation must be to stand in the owners', or stakeholders', shoes. Crucially, though, this implies that what would be morally impermissible for the owners must also be morally impermissible for the agent. The obligation of truthfulness is replicated, not exempted. As most commentators agree, "what is wrong for principals to do directly does not become right when delegated to their agents" (Cohen 2002, 119) and "I cannot (ethically) hire done on my behalf what I would not (ethically) do myself" (Goodpaster 1991, 68; also DeGeorge 1992, 65-66; Bowie and Freeman 1992, 9; Quinn and Jones 1995, 35; Heath 2014, 276, 315-16).

The apologist might rejoin that, whereas the owners are free to choose their own moral position, the manager as agent is bound by undertakings and, specifically, by an implicit promise to maximise profits whatever that takes. But such a promise would itself be morally impermissible and void. Applbaum $(1999,8)$ captures the point well: "The answer cannot simply be that the professional has promised. Whether the promissor is a contract killer or a contract liar, a promise to wrong another has no moral force" (also Quinn and Jones 1995, 35-36; Carson 2010b, 173; Heath 2014, 275).

The fiduciary duty, or principal-agent, defence of lying fails, then, on multiple grounds. Its basic premise that the interests of the principal are best served by lying is highly questionable (see further discussion in section 3.5); its shuffling of responsibility between offending parties cannot erase the wrong suffered by the victim; and its line of argument by extension permits any number of other wrongs that are clearly impermissible. Above all, though, it essentially misinterprets the relationship between principal and agent, a relationship that cannot turn wrong into right.

\subsection{Argument from Practicality}

The final apologist argument is different in character again. It rests not on a question of principle but rather on one of practicality. It insists that lying in a negotiation must be permissible, because a prohibition on such lying is simply infeasible, placing an unworkable burden on the negotiator. The typical test case is the reservation price. Surely, the argument goes, a negotiator cannot be expected to reveal her reservation price. That would be to unreasonably weaken her hand. And yet, the argument continues, if she is asked "is that your best offer?" and does not reply in the affirmative-even if that is a lie - then she has done just that. She has undermined her own negotiating position. This pragmatic defence of lying is, as far as I can tell, absent from the philosophical literature, but it is regularly cited by practitioners actually involved in negotiation. When challenged as to why they have claimed dishonestly that their offer was "best" or "final," they are prone to reply along the lines of "well, what else was I supposed to say? If I'd said anything 
different, the other side would have known I had more in my pocket!" I will offer two responses to this argument from practicality: a principled response and a pragmatic response.

The principled response might be briefly characterised as "so what?": doing the right thing often is difficult and disadvantageous, but that doesn't mean it's not the right thing. After all, there are plenty of parallel instances where we would not consider potential disadvantage an adequate justification for morally impermissible behaviour. For example, few would accept that because not participating in fraud, insider trading, or corporate espionage disadvantages your position, such disadvantage justifies, or even excuses, you committing such acts. Furthermore, it is quite normal for companies to incur significant costs pursuing corporate citizenship/CSR agendas that go well beyond the requirements of the law (for an extensive list, see Norman 2011, 49). Adopting a similar logic, perhaps we should conclude that, however disadvantageous a prohibition on lying may be, that is the necessary price demanded by morally permissible conduct.

But I accept that there is something unsatisfactory about this principled responseat least when unsupported by a practical course of action. As Badaracco $(2002,39)$ says, "no one manages to climb even part way up the greasy pole without paying close attention to his or her interests." For a business manager to act consistently against their self-interest would be a recipe for Darwinian extinction or, as Badaracco puts it, "martyrdom and self-immolation" (52). A moral requirement that they do so would be ultimately self-defeating. There needs to be a more practical alternative (Provis 2000b, 10-11).

This is a challenging area, but experienced negotiators have found a practical way to meet this challenge — at least to a significant degree. They tend to avoid statements about their reservation price, including references to "best" or "final" offers. Instead, they seek to establish a consistent pattern of behaviour that means that a refusal to engage in such statements does not signal one thing or the other. They focus on the offer they are prepared to put forward at any given moment, reflecting the other terms and conditions and the knowledge then in their possession. They have a tendency to say less rather than more, to focus on the facts rather than the rhetoric. They certainly do not volunteer the "whole truth." Instead, they withhold any comment on their reservation price and simply engage in a series of offers and counteroffers, none of which constitutes lying (Boatright 1992, 72; Carson 2005, 402). This approach is not dissimilar to that Shell $(2018,185-86,189)$ advocates in his book on negotiating strategy, Bargaining for Advantage.

How might this play out in our opening scenario? How might Zach negotiate effectively without lying? Well, one could imagine a conversation that goes something like this:

AвE: Zach, we would be looking for a discount. Only fair to tell you.

ZACH: Abe, I know where you're coming from, but this is the most advanced machine of its generation and we are expecting a lot of interest. You know our price.

$\mathrm{ABE}:$ Yes, but is that your best price? 
ZACH: Well, you're negotiating. That's fair enough. But you know me by now, and I never discuss "best" or "final" offers. That just makes for nonsense and bluster. You know the price we're asking. And this is an excellent machine. I believe it can make a real difference on your production line. It's worth paying up for.

ABE: Yes, but how much do I need to pay up?

ZACH: Well, how much are you prepared to pay up? [Zach slaps Abe on the arm.] Come on, let's discuss this over a beer.

Zach has not lied, nor has he undermined his negotiating position. Yes, he has signalled some preparedness to compromise. But Abe almost certainly knew he would get some discount, and Zach has really given nothing else away. Zach has also managed to put Abe into the position of being obliged to make the next move, a key strategy favoured by honed negotiators. Furthermore, Zach has reinforced his personal standing and integrity with Abe, which may be significant in future dealings. By contrast, in the original scenario, Zach makes a categorical statement that his boss will not permit a discount, only an hour later to reveal by his own action in granting a discount that he was previously lying to Abe. Such behaviour, repeated over time, will lead Abe to discount much of what Zach says, even when he is telling the truth.

The preceding case illustrates an important point: lying might confer a short-term advantage, but it also incurs long-term costs for the liar that include loss of trust, retribution, and diminished reputation (Shapiro and Bies 1994, 18, 29-31; Friedman and Shapiro 1995, 251; O'Connor and Carnevale 1997, 513-14; Boles, Croson, and Murnighan 2000, 254-55; Croson, Boles, and Murnighan 2003, 157-58; Tyler, Feldman, and Reichert 2006, 75; Boero et al. 2009, 876; Rogers et al. 2017, 465-66). Maurice Schweitzer, John Hershey, and Eric Bradlow (2006) have researched the impact of lying on trust in particular. They find that while trust can generally be restored following a period of untrustworthy behaviour, "trust harmed by deception never fully recovers" (15).

More broadly, Joseph Reitz, James Wall, and Mary Sue Love (1998, 13) enumerate four significant costs in lying: 1) "rigidity in future negotiations"- the inability to alter one's offer, having initially adopted a dishonest position; 2) "a damaged relationship with the opponent" once falsity is uncovered; 3) "a sullied reputation" in the wider community; and, in their view most important of all, 4) "lost opportunities"- the failure to identify mutually beneficial trade-offs because of false signalling around the value attached to different elements being negotiated.

This fourth component, the ability through open and honest debate to find mutually beneficial outcomes, has received particular attention. Such mutual gains bargaining (MGB), as it has been termed, was first popularised by Roger Fisher and William Ury in 1981 (Fisher, Ury, and Patton 2011) and has since become the subject of an extensive literature, with a notable focus on labour negotiations. Beyond simply increasing the resource to be divided, Dean Pruitt (1983) identifies four strategies for delivering MGB — or "integrative agreements," as he prefers to call them. The detail of these strategies is unimportant here. The crucial thing common to them all is that they rely on an open exchange of information, for example, "information about the nature of the two parties' interests and their 
priorities among these interests" (41). It is exactly this sort of information exchange, and the consequent value created, that the liar risks forgoing.

The apologist's appeal to practical necessity rests on an erroneous assumption that those who fare best in negotiations are what Andrea Schneider (2000, 24-28) labels " 'Rambo' negotiators." In her study of that perhaps most adversarial of all professions, the law, Schneider found the exact opposite was the case. In her survey of 690 lawyers in Milwaukee and Chicago, 53 per cent of "adversarial" (i.e., "Rambo") lawyers were rated by their peers as "ineffective," while the equivalent for "problem solving" (i.e., non-"Rambo") lawyers was under 4 per cent. Aggressive negotiating tactics, including lying, are not necessarily outcome maximising, even for the aggressor (Burr 2001, 10; Cohen 2002, 118).

A similar conclusion emerges from a simulated market entry exercise conducted by Rebecca Guidice, G. Stoney Alder, and Steven Phelan (2009) among 112 undergraduate and MBA students. In successive rounds, students declared their intent (or not) to enter the market and then acted accordingly (or not). Points were awarded for entering an under-supplied market and deducted for entering an over-supplied one. In effect, the students were negotiating with each other for the right to participate in the market. A declaration of intent that was different from the subsequent action was rated a "bluff" (in this case, a knowingly false statement intended to deceive, i.e., a lie). Guidice, Alder, and Phelan found that such "bluffing had a significant negative effect on performance" and concluded that "while it is often assumed that bluffing is advantageous, it actually is not" (547).

It is widely believed that it is the more experienced, "street-wise" negotiators who are most inclined to lie, but again, this is the inverse of the truth. Attitudinal studies, across several cultures, have reported a greater reluctance to lie among older negotiators (Volkema 2004, 75; Morse and Cohen 2019, 15). Deepak Malhotra and Max Bazerman (2007, 213), too, have found that their more seasoned executive students are much less likely to condone lying in negotiations than their younger MBA students. They attribute this to the fact that their executive students "have many more years of negotiation experience" and "have witnessed and experienced the consequences of negotiating in bad faith." Asked about lying, Malhotra and Bazerman's advice is crystal clear: "Don't do it. Don't ever lie" (Malhotra and Bazerman 2007, 218; also Nyerges 1987, 21, 24; Shell 2018, 194).

However, to conclude that lying is invariably to the disadvantage of the liar-that "honesty always pays" - would be unduly sanguine. There is evidence that lying can confer at least short-term advantage (O’Connor and Carnevale 1997, 504; Aquino 1998, 208; Croson, Boles, and Murnighan 2003, 156-57; Gaspar and Schweitzer 2013, 161; Rogers et al. 2017, 464-65; Gunia and Levine 2019, 134; Gaspar, Methasani, and Schweitzer 2019, 64, 74). It often goes undetected (Ekman and O'Sullivan 1991, 916; Bond and DePaulo 2006, 222, 230; Adler 2007, 70). And there are clear cases of negotiation that are inherently single-shot, such as the purchase or sale of a used car or a transaction in a tourist bazaar. In these cases, we must accept that lying may give some partial benefit to the liar. But this does not characterise most business negotiations. In the main, business negotiations are held between parties in the same or related industries or communities. Such negotiations 
are not by their nature single-shot but instead form part of an extended relationship or at least involve parties who know of each other through reputation. Here the longterm costs of lying are much greater.

In summary, there are methods available to protect one's negotiating position while refraining from lying. And lying does not come free; it carries costs of its own, especially in the longer term. Experienced negotiators, like the economist and merchant banker John Rutledge (1996, 78), know that, far from being systematically disadvantaged, "nice guys often finish first." And the inverse of that holds too. As another financier, the Goldman Sachs whistle-blower Greg Smith (2012), declared in the New York Times, "if clients don't trust you they will eventually stop doing business with you. It doesn't matter how smart you are."

But the apologist may raise a further objection. The practical strategy, outlined herein, could lead to the accusation of inconsistency. The apologist might argue that it relies on an untenable moral distinction between active lying and passive withholding of information. Why, she may ask, is passively withholding information from the other side morally any different from actively lying to them? Both can prove seriously misleading. And clearly the consequences for the counterparty in each case can be equally damaging.

This is a complex area. Some radical consequentialists, like Peter Singer (1972, $229-43 ; 2009,15-16$ ), are reluctant to accept that there is any morally significant difference between doing (acts of commission) and merely allowing (acts of omission). And yet, if we examine the fundamental objections to lying, whether they be Kantian, consequentialist, or aretaic, it does seem reasonable to draw such a distinction. From a Kantian perspective, lying uses others as a mere means, while withholding information only represents a refusal to be useful to others, that is, a refusal to subordinate our ends to their ends-something that is arguably supererogatory. Equally from a consequentialist perspective, withholding information, except in the most egregious cases, does not engender the same broad mistrust as does lying. It does not fundamentally threaten social cooperation and cohesion. Indeed, it seems that some degree of withholding of information is essential to that social cohesion (Sullivan 1984, 11; Sunstein 2021, 33). For example, it is hard to imagine a functioning society where people volunteered all their thoughts about each other all the time-from sneering contempt to unbridled lust. The film Liar, Liar provides a humorous illustration of just that (Shadyac 1997). Virtue ethicists in their turn might argue that, whereas a refusal to lie is part of the virtue of honesty, willingly divulging one's reservation price would betray an excessively open character, bordering on naivety. In Aristotelian terms, a simple refusal to lie, but to say no more, might reasonably be seen to sit at the golden mean between opposing vices of manipulative lying, on one hand (a deficiency of truthfulness), and a mindless and naive refusal to withhold information which one is not obliged to disclose, on the other (an excess of truthfulness). Furthermore, this ethical distinction between lying and simply withholding information draws some support from the law. As Chris Provis (2000a, 155) points out, "if questioned by the police, I may not lie to them, but I have the right to remain silent, and fundamentally the same distinction is available to negotiators." 
In summary, passively withholding information is morally different from actively lying. Not lying, but at the same time refusing to reveal, for example, one's reservation price, is therefore a morally viable option. The apologist's argument from practicality is neutralised, because there are means available to the ethical negotiator that allow her to protect her position. And there are many other practical benefits that accrue from refusing to lie.

\section{CONCLUSION}

My claim is that lying in business negotiations is pro tanto wrong and no less wrong than lying in other contexts and, furthermore, that such lying is both unnecessary and, in most cases, ultimately to the disadvantage of the negotiator. I have focussed on business negotiations but suggested, at various points, that this may extend to other professions as well, including the law, trade unionism, and even government.

My case is simply that lying in business or professional negotiations is no different from any other form of lying and is therefore equally wrong. This is a reasonable presumption in the absence of any sustainable argument that there is a moral difference. My own argument has been largely one of refutation. The burden of proof rests with the apologist, who seeks to create a special dispensation for lying in business negotiations. The apologist must show there is a disanalogy, a moral difference that distinguishes business negotiations from other social contexts. Failing that, consistency requires that they be treated alike.

I have analysed the five main arguments put forward by apologists in defence of this moral difference: arguments based on consent, self-defence, the "greater good," fiduciary duty, and practicality. I have sought to demonstrate that each is seriously flawed. The argument from consent looks unsustainable, if that consent is made explicit, and anyway fails empirically, because such consent is insufficiently universal. The more restrictive argument from self-defence is seldom, if ever, applicable, as even its most vocal proponent accepts, while the more permissive argument from self-defence would appear to justify all sorts of pre-emptive, unprovoked attacks that are clearly morally impermissible. And the argument based on the promotion of the "greater good," while it does support the importance of the negotiating process, cannot justify lying, because lying, far from being an essential element of that negotiating process, actually threatens to undermine it and society at large. Meanwhile, the argument from fiduciary duty fails too, because it cannot erase the wrong inflicted on the victim, because it by extension permits any number of other wrongs that are clearly impermissible, and because it fundamentally misinterprets the relationship between principal and agent. Finally, the argument from practicality fails to address the moral principle involved and, anyway, is circumvented, because there are practical means available for protecting a party's negotiating position while avoiding lying. Furthermore, and contrary to the apologist position, the weight of evidence suggests that not lying is, in most cases, the more advantageous strategy. Far from being a burdensome constraint, the imperative not to lie is generally in the self-interest—especially the long-term self-interest—of the negotiator. 
I conclude that my claim stands. It is time for those involved in business negotiations to recognise that a lie is a lie. The moral rules that apply to business negotiators are the same moral rules that apply in society at large. It was Carr's article of 1968, above all, that catalysed this whole debate. So it is fitting to end with a reply to that article from the wife of a businessman, one Mrs Philip D. Ryan of Wyckoff, New Jersey: "Plainly the true meaning of a man's job escapes Mr. Carr. A man's work is not a card game; it is the sum of his self-expression, his life's effort, his mark upon the world, his pride. Men who ... buy their business at the cost of their integrity ... had best stick to card games and send their wives out to work" (Blodgett 1968, 166).

\section{Acknowledgments}

I am grateful to Business Ethics Quarterly's former editor in chief, Bruce Barry, and three anonymous reviewers, together with Michael Otsuka, Susanne Burri, and Alex Voorhoeve, for their constructive engagement with this article.

\section{REFERENCES}

Abeler, Johannes, Daniele Nosenzo, and Collin Raymond. 2019. "Preferences for TruthTelling." Econometrica 87 (4): 1115-53.

Adler, Robert. 2007. "Negotiating with Liars." MIT Sloan Management Review 48 (4): 69-74.

Akerlof, George. 1970. “The Market for 'Lemons': Quality Uncertainty and the Market Mechanism." Quarterly Journal of Economics 84 (3): 488-500.

Allhoff, Fritz. 2003. "Business Bluffing Reconsidered.” Journal of Business Ethics 45 (4): 283-89.

Applbaum, Arthur. 1999. Ethics for Adversaries: The Morality of Roles in Public and Professional Life. Princeton, NJ: Princeton University Press.

Aquino, Karl. 1998. "The Effects of Ethical Climate and the Availability of Alternatives on the Use of Deception during Negotiation." International Journal of Conflict 9 (3): 195-217.

Aquino, Karl, and Thomas Becker. 2005. "Lying in Negotiations: How Individual and Statistical Factors Influence the Use of Neutralization Strategies." Journal of Organizational Behavior 26 (6): 661-79.

Ariely, Dan. 2009. Predictably Irrational. Rev. and exp. ed. London: Thorsons.

Arrow, Kenneth. 1973. "Social Responsibility and Economic Efficiency." Public Policy 21: 303-17.

Augustine. (395) 2016. "De Mendacio," translated by H. Browne. In Lying and Truthfulness, edited by Kevin DeLapp and Jeremy Henkel, 6-35. Indianapolis, IN: Hackett.

Badaracco, Joseph, Jr. 1997. Defining Moments: When Managers Must Choose between Right and Right. Boston: Harvard Business School Press.

Badaracco, Joseph, Jr. 2002. Leading Quietly: An Unorthodox Guide to Doing the Right Thing. Boston: Harvard Business School Press.

Banai, Moshe, Abraham Stefanidis, Ana Shetach, and Mehmet Ferhat Özbek. 2014. "Attitudes toward Ethically Questionable Negotiation Tactics: A Two-Country Study." Journal of Business Ethics 123 (4): 669-85. 
Barnes, John. 1994. A Pack of Lies: Towards a Sociology of Lying. New York: Cambridge University Press.

Beach, John. 1985. "Bluffing: Its Demise as a Subject unto Itself." Journal of Business Ethics 4 (3): 191-96.

Blodgett, Timothy. 1968. "Showdown on 'Business Bluffing." Harvard Business Review, May-June, 162-70.

Boatright, John. 1992. "Morality in Practice: Dees, Cramton, and Brer Rabbit on a Problem of Applied Ethics." Business Ethics Quarterly 2 (1): 63-73.

Boero, Riccardo, Giangiacomo Bravo, Marco Castellani, and Flaminio Squazzoni. 2009. "Reputational Cues in Repeated Trust Games.” Journal of Socio-Economics 38: 871-77.

Bok, Sissela. 1999. Lying: Moral Choice in Public and Private Life. 2nd Vintage Books ed. New York: Vintage Books.

Boles, Terry, Rachel Croson, and Keith Murnighan. 2000. "Deception and Retribution in Repeated Ultimatum Bargaining." Organizational Behavior and Human Decision Processes 83 (2): 235-59.

Bond, Charles, and Bella DePaulo. 2006. “Accuracy of Deception Judgments.” Personality and Social Psychology Review 10 (3): 214-34.

Bowie, Norman. 1985. "Should Collective Bargaining and Labor Relations Be Less Adversarial?" Journal of Business Ethics 4 (4): 283-91.

Bowie, Norman, and R. Edward Freeman. 1992. "Ethics and Agency Theory: An Introduction." In Ethics and Agency Theory: An Introduction, edited by Norman Bowie and R. Edward Freeman, 3-22. New York: Oxford University Press.

Brandts, Jordi, and Gary Charness. 2003. "Truth or Consequences: An Experiment." Management Science 49 (1): 116-30.

Burr, Anne. 2001. "Ethics in Negotiations: Does Getting to Yes Require Candor?" Dispute Resolution Journal, May-July, 9-15.

Carr, Albert. 1968. "Is Bluffing in Business Ethical?" Harvard Business Review, January-February, 143-53.

Carson, Thomas. 1993. "Second Thoughts on Bluffing." Business Ethics Quarterly 3 (4): $317-41$.

Carson, Thomas. 2005. "The Morality of Bluffing: A Reply to Allhof." Journal of Business Ethics 56 (4): 399-403.

Carson, Thomas. 2006. “The Definition of Lying.” Nous 40 (2): 284-306.

Carson, Thomas. 2010a. "Deception and Information Disclosure in Business and Professional Ethics." In The Oxford Handbook of Business Ethics, edited by George Brenkert and Tom Beauchamp, 335-65. New York: Oxford University Press.

Carson, Thomas. 2010b. Lying and Deception: Theory and Practice. Oxford: Oxford University Press.

Carson, Thomas, Richard Wokutch, and Kent Murrmann. 1982. "Bluffing in Labor Negotiations: Legal and Ethical Issues." Journal of Business Ethics 1 (1): 13-22.

Chisholm, Roderick, and Thomas Feehan. 1977. "The Intent to Deceive." Journal of Philosophy 74 (3): 143-59.

Cohen, Jonathan. 2002. "The Ethics of Respect in Negotiation.” Negotiation Journal, April, 115-20.

Cooper, Ricky, Michael Davis, and Ben Van Vliet. 2016. "The Mysterious Ethics of HighFrequency Trading." Business Ethics Quarterly 26 (1): 1-22.

Croson, Rachel, Terry Boles, and Keith Murnighan. 2003. "Cheap Talk in Bargaining Experiments: Lying and Threats in Ultimatum Games." Journal of Economic Behavior and Organization 51: 143-59. 
Curtis, Charles. 1951. "The Ethics of Advocacy.” Stanford Law Review 4 (1): 3-23.

Darwall, Stephen. 1977. "Two Kinds of Respect." Ethics 88 (1): 36-49.

Davis, Nathaniel. 2016. "If War Can Have Ethics, Wall Street Can, Too." New York Times, October 3.

Dees, Gregory, and Peter Cramton. 1991. "Shrewd Bargaining on the Moral Frontier: Toward a Theory of Morality in Practice." Business Ethics Quarterly 1 (2): 135-67.

Dees, Gregory, and Peter Cramton. 1995. "Deception and Mutual Trust: A Reply to Strudler." Business Ethics Quarterly 5 (4): 823-32.

DeGeorge, Richard. 1992. "Agency Theory and the Ethics of Agency." In Ethics and Agency Theory, edited by Norman Bowie and Edward Freeman, 59-72. Oxford: Oxford University Press.

Ekman, Paul, and Maureen O'Sullivan. 1991. “Who Can Catch a Liar?” American Psychologist 46 (9): 913-20.

Erat, Sanjiv, and Uri Gneezy. 2012. "White Lies.” Management Science 58 (4): 723-33.

Fallis, Don. 2009. "What Is Lying?” Journal of Philosophy 106 (1): 29-56.

Fisher, Roger, William Ury, and Bruce Patton. 2011. Getting to Yes: Negotiating an Agreement without Giving In. 3rd rev. ed. New York: Random House.

Frankfurt, Harry. 2005. On Bullshit. Princeton, NJ: Princeton University Press.

Freeman, R. Edward. 1984. Strategic Management: A Stakeholder Approach. Boston: Pitman.

Friedman, Milton. 1962. Capitalism and Freedom. Chicago: University of Chicago Press.

Friedman, Milton. 1970. "The Social Responsibility of Business Is to Increase Profits." New York Times Magazine, September 13.

Friedman, Raymond. 1993. "Bringing Mutual Gains Bargaining to Labor Negotiations: The Role of Trust, Understanding, and Control." Human Resources Management 32 (4): 435-59.

Friedman, Raymond, and Debra Shapiro. 1995. "Deception and Mutual Gains Bargaining: Are They Mutually Exclusive?" Negotiation Journal, July, 243-53.

Gaspar, Joseph, Emma Levine, and Maurice Schweitzer. 2015. "Why We Should Lie." Organizational Dynamics 44: 306-9.

Gaspar, Joseph, Redona Methasani, and Maurice Schweitzer. 2019. "Fifty Shades of Deception: Characteristics and Consequences of Lying in Negotiations." Academy of Management Perspectives 33 (1): 62-81.

Gaspar, Joseph, and Maurice Schweitzer. 2013. "The Emotion Deception Model: A Review of Deception in Negotiation and the Role of Emotion in Deception." Negotiation and Conflict Management Research 6 (3): 160-79.

Gerlach, Philipp, Kinneret Teodorescu, and Ralph Hertwig. 2019. "The Truth about Lies: A Meta-analysis on Dishonest Behavior." American Psychological Association Psychological Bulletin 145 (1): 1-44.

Goodpaster, Kenneth. 1991. "Business Ethics and Stakeholder Analysis." Business Ethics Quarterly 1 (1): 53-73.

Gorlin, Rena, ed. 1990. Codes of Professional Responsibility. 2nd ed. Washington, DC: Bureau of National Affairs.

Gneezy, Uri. 2005. "The Role of Consequences." American Economic Review 95 (1): 384-94.

Guidice, Rebecca, G. Stoney Alder, and Steven Phelan. 2009. "Competitive Bluffing: An Examination of a Common Practice and Its Relationship with Performance." Journal of Business Ethics 87 (4): 535-53. 
Gunia, Brian, and Emma Levine. 2019. "Deception as Competence: The Effect of Occupational Stereotypes on the Perception and Proliferation of Deception." Organizational Behavior and Human Decision Processes 152: 122-37.

Hare, R. M. 1992. "One Philosopher's Approach to Business and Professional Ethics." Business and Professional Ethics Journal 11 (2): 3-19.

Harris, Sam. 2013. Lying. Opelousas, LA: Four Elephants Press.

Heath, Joseph. 2014. Morality, Competition, and the Firm: The Market Failures Approach to Business Ethics. New York: Oxford University Press.

Heath, Joseph. 2018. "'But Everyone Else Is Doing It': Competition and Business SelfRegulation." Journal of Social Philosophy 49 (4): 516-35.

Hersch, Gil. 2020. "You Can Bluff but You Should Not Spoof." Business and Professional Ethics Journal 39 (2): 207-24.

Hess, David, and Thomas Dunfee. 2007. "The Kasky-Nike Threat to Corporate Social Reporting: Implementing a Standard of Optimal Truthful Disclosure as a Solution." Business Ethics Quarterly 17 (1): 5-32.

Holley, David. 1998. "Information Disclosure in Sales.” Journal of Business Ethics 17 (6): 631-41.

John, Leslie. 2016. "Managing Yourself: How to Negotiate with a Liar." Harvard Business Review, July-August, 114-17.

Kant, Immanuel. (1795) 1917. Perpetual Peace. 3rd ed. Translated by M. Campbell Smith. London: George Allen and Unwin.

Kant, Immanuel. (1797) 2016. "On a Supposed Right to Lie because of Philanthropic Concerns," translated by James Ellington. In Lying and Truthfulness, edited by Kevin DeLapp and Jeremy Henkel, 81-86. Indianapolis, IN: Hackett.

Koehn, Daryl. 1997. "Business and Game-Playing: The False Analogy." Journal of Business Ethics 16 (12/13): 1447-52.

Kramer, Roderick. 2009. "Rethinking Trust.” Harvard Business Review, June, 69-77.

Levine, Emma, and Maurice Schweitzer. 2015. "Prosocial Lies: When Deception Breeds Trust." Organizational Behavior and Human Decision Processes 126: 88-106.

Lewicki, Roy. 1983. "Lying and Deception: A Behavioral Model." In Negotiating in Organisations, edited by Max Bazerman and Roy Lewicki, 68-90. Beverly Hills, CA: Sage.

Ma, Zhenzhong. 2010. "The SINS in Business Negotiations: Explore the Cross-Cultural Differences in Business Ethics between Canada and China." Journal of Business Ethics 91: 123-35.

Ma, Zhenzhong, Dapeng Liang, and Honghui Chen. 2013. "Negotiating with the Chinese: Are They More Likely to Use Unethical Strategies?" Group Decision and Negotiation 22: 641-55.

MacIntyre, Alasdair. 1994. "Truthfulness, Lies, and Moral Philosophers: What Can We Learn from Mill and Kant?” Tanner Lectures on Human Values, Princeton, University, Princeton, NJ, April 6 and 7.

Mahon, James. 2015. "The Definition of Lying and Deception." Stanford Encyclopedia of Philosophy, edited by Edward N. Zalta. https://plato.stanford.edu/entries/lying-defi nition/.

Malhotra, Deepak, and Max Bazerman. 2007. Negotiation Genius. New York: Bantam Books.

Michelman, James. 1983. "Deception in Commercial Negotiation." Journal of Business Ethics 2 (4): 255-62. 
Mitchell, Vincent-Wayne, and Joseph Chan. 2002. "Investigating UK Consumers' Unethical Attitudes and Behaviours." Journal of Marketing Management 18: 5-26.

Morse, Lily, and Taya Cohen. 2019. "Moral Character in Negotiation." Academy of Management Perspectives 33 (1): 12-25.

Murnighan, Keith, Linda Babcock, Leigh Thompson, and Madan Pillutla. 1999. "The Information Dilemma in Negotiations: Effects of Experience, Incentives, and Integrative Potential." International Journal of Conflict Management 10 (4): 313-39.

Norman, Wayne. 2011. "Business Ethics as Self-Regulation: Why Principles That Ground Regulations Should Be Used to Ground Beyond-Compliance Norms as Well." Journal of Business Ethics 102 (Suppl. 1): 43-57.

Nyerges, Janos. 1987. "Ten Commandments for a Negotiator." Negotiation Journal, January, 21-27.

O'Connor, Kathleen, and Peter Carnevale. 1997. "A Nasty but Effective Negotiation Strategy: Misrepresentation of a Common-Value Issue." Personality and Social Psychology Bulletin 23: 504-15.

Olekalns, Mara, Carol Kulik, and Lin Chew. 2014. "Sweet Little Lies: Social Context and the Use of Deception in Negotiation.” Journal of Business Ethics 120 (1): 13-26.

Peppet, Scott. 2002. "Can Saints Negotiate? A Brief Introduction to the Problems of Perfect Ethics in Bargaining." Harvard Negotiation Law Review 7: 83-96.

Piker, Andrew. 2002. "Ethical Immunity in Business: A Response to Two Arguments." Journal of Business Ethics 36: 337-46.

Preston, Ivan. 1994. The Tangled Web They Weave: Truth, Falsity and Advertisers. Madison: University of Wisconsin Press.

Provis, Chris. 2000a. "Ethics, Deception and Labor Negotiation." Journal of Business Ethics 28 (2): $145-58$.

Provis, Chris. 2000b. "Honesty in Negotiation." Business Ethics: A European Review 9 (1): 3-12.

Pruitt, Dean. 1983. “Achieving Integrated Agreements.” In Negotiation in Organizations, edited by Max Bazerman and Roy Lewicki, 35-50. Beverly Hills, CA: Sage.

Quinlan, Michael. 1993. "Ethics in the Public Service." Governance: An International Journal of Policy and Administration 6 (4): 538-58.

Quinn, Dennis, and Thomas Jones. 1995. "An Agent Morality View of Business Policy." Academy of Management Review 20 (1): 22-42.

Rao, Asha, and Stuart Schmidt. 1998. "A Behavioral Perspective on Negotiating International Alliances." Journal of International Business Studies 29 (4): 665-93.

Rawls, John. 1971. A Theory of Justice. Oxford: Oxford University Press.

Rees, McKenzie, Ann Tenbrunsel, and Max Bazerman. 2019. "Bounded Ethicality and Ethical Fading in Negotiations: Understanding Unintended Unethical Behavior." Academy of Management Perspectives 33 (1): 26-42.

Reitz, Joseph, James Wall, and Mary Sue Love. 1998. "Ethics in Negotiation: Oil and Water or Good Lubrication?” Business Horizons, May-June, 5-14.

Rivers, Cheryl, and Anne Louise Lytle. 2007. "Lying, Cheating Foreigners!! Negotiation Ethics across Cultures." International Negotiation 12: 1-28.

Rivers, Cheryl, and Roger Volkema. 2013. "East-West Differences in 'Tricky' Tactics: A Comparison of the Tactical Preferences of Chinese and Australian Negotiators." Journal of Business Ethics 115 (1): 17-31.

Rogers, Todd, Richard Zeckhauser, Francesco Gino, and Michael Norton. 2017. "Artful Paltering: The Risks and Rewards of Using Truthful Statements to Mislead Others." Journal of Personality and Social Psychology 112 (3): 456-73. 
Rutledge, John. 1996. "The Portrait on My Office Wall.” Forbes, December 30.

Saul, Jennifer. 2012. Lying, Misleading and What Is Said: An Exploration in Philosophy of Language and in Ethics. Oxford: Oxford University Press.

Schneider, Andrea. 2000. "Perception, Reputation and Reality: An Empirical Study of Negotiation Skills." Dispute Resolution Magazine, Summer, 24-28.

Schweitzer, Maurice, and Rachel Croson. 1999. "Curtailing Deception: The Impact of Direct Questions on Lies and Omissions." International Journal of Conflict Management 10 (3): 225-48.

Schweitzer, Maurice, John Hershey, and Eric Bradlow. 2006. "Promises and Lies: Restoring Violated Trust." Organizational Behavior and Human Decision Processes 101: $1-19$.

Shadyac, Tom, dir. 1997. Liar, Liar. United States: Universal Studios.

Shapiro, Debra, and Robert Bies. 1994. "Threats, Bluffs, and Disclaimers in Negotiations." Organizational Behavior and Human Decision Processes 60: 14-35.

Shell, Richard. 1991. "When Is It Legal to Lie in Negotiations?" Sloan Management Review 32 (3): 93-101.

Shell, Richard. 2018. Bargaining for Advantage: Negotiation Strategies for Reasonable People. 3rd ed. New York: Penguin.

Singer, Peter. 1972. "Famine, Affluence, and Morality." Philosophy and Public Affairs 1 (3): 229-43.

Singer, Peter. 2009. The Life You Can Save. London: Picador.

Smith, Adam. (1776) 2012. Wealth of Nations. New York: Wordsworth.

Smith, Greg. 2012. "Why I Am Leaving Goldman Sachs." New York Times, March 14.

Sobral, Filipe, and Gazi Islam. 2013. "Ethically Questionable Negotiating: The Interactive Effects of Trust, Competitiveness, and Situation Favorability on Ethical Decision Making." Journal of Business Ethics 117 (2): 281-96.

Sorensen, Roy. 2007. "Bald-Faced Lies! Lying without the Intent to Deceive." Pacific Philosophical Quarterly 88: 251-64.

Strudler, Alan. 1995. “On the Ethics of Deception in Negotiation.” Business Ethics Quarterly 5 (4): 805-22.

Strudler, Alan. 2005. "Deception Unraveled." Journal of Philosophy 102 (9): 458-73.

Sullivan, Roger. 1984. "A Response to 'Is Business Bluffing Ethical?'” Business and Professional Ethics Journal 3 (2): 1-21, 23.

Sunstein, Cass. 2021. Liars: Falsehoods and Free Speech in an Age of Deception. New York: Oxford University Press.

Tenbrunsel, Ann. 1998. "Misrepresentation and Expectations of Misrepresentation in an Ethical Dilemma: The Role of Incentives and Temptation." Academy of Management Journal 41 (3): 330-39.

Tenbrunsel, Ann, and David Messick. 2004. "Ethical Fading: The Role of Self-Deception in Unethical Behavior.” Social Justice Research 17 (2): 223-36.

Triandis, Harry, Peter Carnevale, Michele Gelfand, Christopher Robert, Arzu Wasti, Tahira Probst, Emiko Kashima et al. 2001. "Culture and Deception in Business Negotiations: A Multilevel Analysis." International Journal of Cross Cultural Management 1 (1): 73-90.

Tyler, James, Robert Feldman, and Andreas Reichert. 2006. "The Price of Deceptive Behavior: Disliking and Lying to People Who Lie to Us." Journal of Experimental Psychology 42: 69-77.

US Holocaust Memorial Museum. 2021. "Nuremberg Trials.” In Holocaust Encyclopedia. https://encyclopedia.ushmm.org/content/en/article/the-nuremberg-trials. 
Volkema, Roger. 2004. "Demographic, Cultural, and Economic Predictors of Perceived Ethicality of Negotiation Behavior: A Nine-Country Analysis." Journal of Business Research 57: 69-78.

Volkema, Roger, Denise Fleck, and Agnes Hofmeister-Toth. 2004. "Ethicality in Negotiation: An Analysis of Attitudes, Intentions, and Outcomes." International Negotiation 9: $315-39$.

Wesley, John. (1785) 1831. “Sermon 90: An Israelite Indeed.” In The Works of the Reverend John Wesley, A.M., edited by John Emory, 276-77. New York: J. Emory and B. Waugh, for the Methodist Episcopal Church.

Williams, Bernard. 2002. Truth and Truthfulness: An Essay in Genealogy. Princeton, NJ: Princeton University Press.

Zhang, Jian-Dong, Leigh Anne Liu, and Wu Liu. 2015. "Trust and Deception in Negotiation: Culturally Divergent Effects." Management and Organization Review 11 (1): 123-44.

Charles N.C. Sherwood, MA (Cantab), MBA (Harvard), MSc (LSE) (c.n.sherwood@1se. ac.uk), worked at the Boston Consulting Group prior to a thirty-year career in private equity. As a founder partner of Permira, he was engaged in all aspects of the firm's business, ultimately chairing the holding company board. He played an extensive part in leading the firm's negotiating teams. He is currently a PhD student at the London School of Economics and Political Science, focusing on the ethics of negotiation.

This is an Open Access article, distributed under the terms of the Creative Commons Attribution licence (https://creativecommons.org/licenses/by/4.0/), which permits unrestricted re-use, distribution, and reproduction in any medium, provided the original work is properly cited. 